\title{
Articulando escolas de pensamento estratégico através da tec- nologia da informação
}

\author{
Business strategy schools: is information technology the missing link?
}

Eduardo Augusto de Andrade Ramos ${ }^{1}$

Luiz Antonio Joia ${ }^{2}$

\section{Resumo}

Na medida em que as organizações investem crescentemente em tecnologia da informação (TI) e tal tecnologia influencia cada vez mais os seus processos de negócios, o impacto da utilização da TI no desempenho das organizações tem sido alvo de grande interesse. Para análise desse impacto, diversos modelos têm sido desenvolvidos. Por trás desses modelos, duas grandes escolas de estratégia - consideradas antagônicas - se sobressaem e têm sido utilizadas para modelar o papel da TI na estratégia das organizações: a escola de posicionamento e a escola de recursos. O objetivo deste artigo teórico é propor uma articulação entre essas duas linhas de pensamento estratégico, tendo como elo de ligação o papel estratégico da TI nas firmas. Dessa forma, através de uma abordagem teórico-exploratória, esse artigo formula quatro proposições que visam integrar essas duas escolas à luz do papel da TI nas organizações, para ajudar acadêmicos e practitioners a melhor entenderem o papel estratégico da TI nas empresas.

Palavras-chave: tecnologia da informação; escola estratégica de posicionamento; escola estratégica de recursos; visão baseada em recursos; recursos de TI; uso estratégico da tecnologia da informação.

\section{Abstract}

As more organizations have increasingly invested in Information Technology (IT) and such technology has influenced their business processes in an increasing way, the role of IT in the performance of organizations has aroused great interest. In order to analyze this impact, several models have been developed. Supporting these models, two important strategy schools - considered to be conflicting with each other - have been used to model the role of IT in the strategy of organizations: the school of positioning and the school of resources. This theoretical article aims to build a bridge between these two strategy schools of thought, using IT as a missing link. Thus, applying a theoretical-exploratory approach, this work unveils four propositions aiming at integrating these two strategy schools, backed by the role of IT in the organizations, so as to help academics and practitioners to better understand the strategic role of IT in the firms.

Key words: information technology; positioning school; resource school; resource-based view; IT resources; strategic use of information technology.

\footnotetext{
${ }^{1}$ Doutorando em Administração pela Fundação Getulio Vargas/Ebape. Mestre em economia pela FGV/EPGE. Diretor do Instituto INFNET. Endereço: Rua São José, 90/20. andar - Rio de Janeiro - RJ - Brasil - CEP: 20010-020. E-Mail : eduardo.ramos@infnet.edu.br.

${ }^{2}$ Doutor em Ciências em Engenharia de Produção (Major: Inovação Tecnológica e Organização Industrial) pela COPPE/UFRJ. Professor da Fundação Getulio Vargas/EBAPE. Endereço : Praia de Botafogo, 190 - sala 526 - Botafogo - Rio de Janeir/RJ - Brasil - CEP: 22250-900 - E-Mail : luizjoia@ @gv.br.

Artigo recebido em agosto de 2006 e aceito para publicação em novembro de 2006.
} 


\section{Introdução}

Na medida em que as organizações investem crescentemente em tecnologia da informação (TI) e tal tecnologia influencia cada vez mais os seus processos de negócios (MEIRELLES, 2003), o impacto da utilização da tecnologia da informação (TI) no desempenho das organizações tem sido alvo de grande interesse de practitioners e acadêmicos (BARNEY, 1991; PORTER; MILLAR, 1985; VARIAN; SHAPIRO, 1999). Assim, uma grande quantidade de estudos visa avaliar a rentabilidade que as organizações obtêm dos seus investimentos em TI, tanto do ponto de vista operacional quanto estratégico (DEDRICK; GURBAXANI; KRAEMER, 2003; MELVILLE; KRAEMER; GURBAXANI., 2004).

Desses estudos, uma relevante conclusão é a de que os resultados obtidos são conflitantes. Tanto há estudos que mostram retornos positivos do investimento em TI (ANDERSON; BANKER; RAVINDRAN, 2003; BRYNJOLFSSON; HITT, 2003), quanto há aqueles que mostram retornos negativos (STRASSMAN, 1990; LAUDAUER, 1995; OSEY-BRYSON; KO, 2004) em relação a indicadores como produtividade, lucratividade e volume de vendas.

O fato de haver vários estudos mostrando retornos negativos da TI e de, simultaneamente, as empresas terem investido em TI grandes somas de recursos nas últimas décadas, levou ao desenvolvimento do conceito do "paradoxo da produtividade", o qual é investigado por diversos autores (DEDRICK; GURBAXANI; KRAEMER, 2003; MELVILLE; KRAEMER; GURBAXANI., 2004; WAINER, 2003).

A questão de fundo, ligada ao estudo desse paradoxo, jaz na avaliação do papel da TI na estratégia das organizações. Para tal, há diversos modelos propostos. Laurindo et al (2001), através de uma meta-análise da literatura, apresentam mais de 20 desses modelos, enquanto Melville, Kraemer e Gurbaxani (2004), analisando mais de 200 artigos, propõem um meta-modelo abrangente para essa questão.

Por trás desses modelos, duas grandes escolas de estratégia se sobressaem e têm sido utilizadas para modelar o papel da TI na estratégia das organizações: a escola de posicionamento ${ }^{3}$ e a escola de recursos, ${ }^{4}$ segundo taxonomia proposta por, entre outros, Mintzberg, Ahlstrand e Lampel (1998).

A escola de posicionamento data da década de 1970, tendo surgido a partir de estudos do Boston Consulting Group (JOIA; FERREIRA, 2005), tornando-se mais tarde a "escola dominante" na área da administração a partir da publicação, em 1980, do livro Competitive strategy, ${ }^{5}$ de Michael Porter (MINTZBERG; AHLSTRAND; LAMPEL, 1998, p.82), autor dos conceitos e obras de maior destaque dessa escola (JOIA; FERREIRA, 2005; MINTZBERG; AHLSTRAND; LAMPEL, 1998).

Por outro lado, a escola de recursos teve sua origem na idéia de Penrose (1959), de que uma organização é um conjunto amplo de recursos, tendo sido inicialmente teorizada para o campo da estratégia por Wernerfelt (MINTBERG; AHLSTRAND; LAMPEL, 1998; JOIA; FERREIRA, 2005; WERNERFELT, 1984). Essa escola deve sua formalização teórica abrangente - e mesmo sua popularização - a Barney (MINTZBERG; AHLSTRAND; LAMPEL, 1998, p.277), através dos seus vários trabalhos acadêmicos (BARNEY, 1991, 1995, 2001).

Embora não haja estudos sobre a quantidade de artigos produzidos seguindo cada uma dessas escolas, a leitura de periódicos na área de gestão estratégica de TI como, por exemplo, o MIS Quarterly, mostra que a escola de recursos tem sido crescentemente utilizada para modelar o papel estratégico da TI. Wade e Hulland (2004, p. 139), por exemplo, exibem uma lista de 24 artigos com tal característica.

\footnotetext{
${ }^{3}$ A escola de posicionamento é também chamada de escola de atividades.

${ }^{4} \mathrm{~A}$ escola de recursos também é conhecida por RBV (resource-based view).

${ }^{5}$ Esse livro foi publicado em português, em 1985, pela Editora Campus.
} 
Dessa forma, o objetivo deste artigo teórico é propor uma articulação entre a escola de recursos e a escola de posicionamento, no que tange ao papel estratégico da TI, de modo a integrar elementos das duas linhas de pensamento estratégico.

\section{Abordagem metodológica}

Esse é um artigo de natureza teórica. Como tal, utiliza referências bibliográficas e as triangulariza a fim de poder gerar algumas observações conclusivas (PATTON, 1990; YIN, 1994).

Da mesma forma, segundo Malhotra (2001, p.106), a finalidade do problema - articular duas escolas de pensamento estratégico através da TI - justifica uma pesquisa de natureza exploratória, já que se busca essa articulação através de proposições desenvolvidas, de modo que sejam testadas em trabalhos futuros.

Assim, após a análise do papel estratégico da TI, tanto segundo a escola estratégica de posicionamento quanto conforme a escola estratégica de recursos, busca-se, interpretativamente, construir pontes - através de proposições - que permitam ligar ambas as escolas, tendo a TI como elo articulador.

Segundo Klein e Myers (1999, p.69), uma análise pode ser caracterizada como interpretativa se assume que o conhecimento da realidade é obtido através de construções sociais como linguagem, consciência, entendimento compartilhado, interpretação de textos, documentos, ferramentas e outros artefatos. Não há, nessa análise, variáveis dependentes ou independentes, mas sim uma preocupação com o sentido que o ser humano dá às situações e conceitos quando eles emergem (KAPLAN; MAXWELL, 1994). Nesse artigo, tal foi praticado, com os autores procurando dar sentido e concatenar os conceitos de outros acadêmicos, à medida que eles emergiam.

Dessa forma, para consecução do seu objetivo, esse artigo estrutura-se metodologicamente da seguinte forma:

- inicialmente, apresenta-se a abordagem estratégica da TI a partir da escola de posicionamento;

- em seguida, repete-se a análise a partir da escola de recursos;

- a partir da análise consolidada do sentido das duas abordagens anteriores, é proposta uma articulação entre as escolas de posicionamento e de recursos, através da inferência exploratória de proposições para testes em pesquisas futuras;

- finalmente, o artigo apresenta uma seção conclusiva, que aborda as implicações do mesmo para a academia e a prática gerencial, além de suas próprias limitações.

Para facilitar a compreensão do artigo pelo leitor e a própria interpretação dos conceitos expressos pelos autores acerca de como essas escolas estratégicas se interpenetram, são usados, no corpo do texto, quadros de exemplos contendo situações reais (quadros 1,3 e 4).

\section{A visão estratégica de TI segundo a escola de posicionamento}

A escola de posicionamento argumenta que a tecnologia da informação afeta a estratégia das empresas através de três formas não excludentes: (1) alterando as estruturas setoriais; (2) permitindo que novos processos ${ }^{6}$ ou elos entre processos sejam estabelecidos, alterando estratégias de custo ou de diferenciação; e (3) gerando alterações nos produtos, o que permite o surgimento de novos negócios ou alterações nos negócios anteriores (PORTER; MILLAR, 1985).

De acordo com visão da escola de posicionamento, as características intrínsecas de um investimento em TI não determinariam se tal investimento traz ou não vantagem competitiva. Como sistemas muito semelhantes ou facilmente copiáveis podem ser utilizados pelas diferentes firmas concorrendo em uma indústria, a sua simples utilização não é uma garantia de vantagem competitiva (PORTER, 2001). Investimentos em TI somente seriam capazes de apoiar a geração de vantagem competitiva se significarem um maior e mais exclusivo acoplamento

\footnotetext{
${ }^{6}$ Neste artigo, as expressões processos e atividades são usadas intercambiavelmente.
} 
de atividades que reflitam um posicionamento único para a firma, valorizado pelos seus clientes (PORTER, 1999a, 2001).

Três grandes instrumentos, bastante populares na academia e no mundo empresarial, são fundamentais nessa escola: o modelo das cinco forças (PORTER, 1986), a cadeia de valores (PORTER, 1999b) e a matriz de intensidade da informação (PORTER; MILLAR, 1985). O primeiro instrumento serve para o escrutínio da ambiência externa a uma empresa, através da atratividade da indústria em que a mesma está inserida, visando suportar o posicionamento estratégico pretendido pela empresa. O segundo instrumento, o modelo da cadeia de valores, destina-se ao escrutínio interno da empresa, permitindo a sua comparação com concorrentes e a avaliação das possibilidades de integração com parceiros e clientes. O terceiro instrumento facilita a avaliação do impacto da TI na empresa.

Em seguida, analisa-se brevemente cada um desses três instrumentos, enfatizando-se as relações dos mesmos com a utilização da TI nas empresas.

A associação do modelo das cinco forças com a TI é relevante, pois a tecnologia da informação propicia para as firmas possibilidades únicas de comunicação e coordenação, o que tem alterado a estrutura de vários setores da economia (PORTER; MILLAR, 1985). Em particular, com o advento da Internet, a inserção da TI nas organizações tem provocado grandes mudanças na arena de competição (EVANS; WURSTER, 1999), como mostra uma versão do modelo das cinco forças apresentada na figura 1 a seguir, que relaciona, para cada uma das forças, as ameaças e oportunidades representadas pela Internet (PORTER, 2001).

\section{Figura 1 - Modelo das cinco forças com a introdução da Internet}

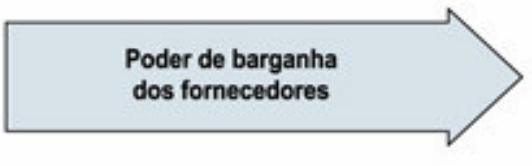

$(+f$.$) "Procurement usando a Internet tende a aumentar$ o poder sobre os fornecodores, portim tambèm oferece aos fomecedores acesso a mais clientes

(-) A Internet provê um canal para os fornecedoces alcancarem os usuários finais

(-) "Internet Procurement" e mercados digitais tendem a oferecer a todas as empresas acesso igual aos fornecedores, reduzindo a diterenciacho

(-) Menores barreiras de entrada e a peoliseraça de competidores aumentam o poder de barganha dos fornecedores

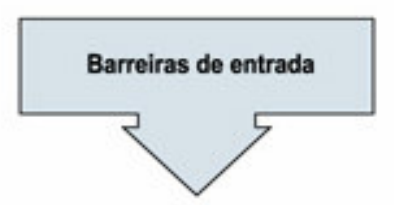

(-) Reduz as barreiras de entrada, como a necessidade de uma forç de vendas, acesso aos canais e instalaçees fisicas - qualquer coisa que a Internet elimina ou toma mais facil reduz as barreiras de entrada

(-) Aplicaçes Internet sło dificeis de se manter proprietárias

(-) Uma mulbiāo de novos entrantes foram trazidos pela Internet, em mulas indústrias

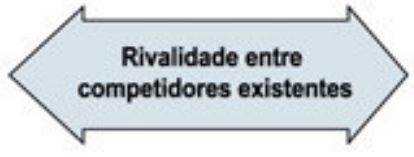

(-) Roduz as diferencas entre os competidones tomado as ofertas dificeis de serem mantidas como proprietainas

(-) Migra a competicalo para o prece

(-) Aumenta geograficamente o mercado, aumentando o numero de competidores

(-) Diminui o custo varidvel em relacalo ao custo $5 \times 0$ aumentando a presslo por descontos no preço

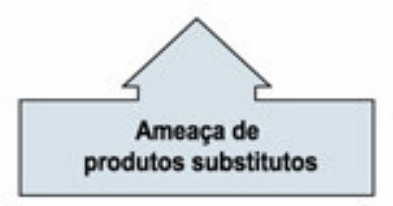

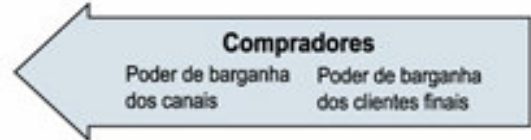

(+) Elimina canais (-) Aumenta o poder poderosos de barganha dos clientes finais

(-) Reduz os custos de mudança
(+) Tomando toda a indistria mals eficiente, a internet pode expandir o mercado

(-) A proliferaçâo de diferentes "approaches" cria novas ameaças de substhulos

Fonte: Porter (2001, p.67), Catalani et al. (2004, p.21).

Segundo a figura 1, a Internet traz 12 ameaças às vantagens competitivas das organizações, uma oportunidade e um efeito incerto. Por ser uma tecnologia baseada em padrões abertos e de domínio público, as iniciativas gerenciais propiciadas pela Internet podem ser facilmente imitadas por concorrentes. Isso significa uma diminuição das barreiras à entrada e uma maior dificuldade na manutenção de diferenciais estratégicos, o que ameaça 
as vantagens competitivas. Por outro lado, a análise da indústria, considerando a presença da Internet e as novas formas de coordenação por ela permitidas, pode revelar oportunidades de novos posicionamentos lucrativos, especialmente, em situações em que uma firma consiga se aproveitar do efeito rede (ver quadro 1 para um exemplo do efeito rede na área de TI).

\section{Quadro 1}

\section{Usando o efeito rede para reforçar uma posição competitiva}

$O$ efeito rede, também conhecido como externalidade de rede, ocorre quando o valor de um determinado produto ou serviço aumenta quanto mais ele é utilizado (EVANS; WURSTER, 1999; VARIAN; SHAPIRO, 1999). Certos tipos de bens ligados à informação, como software, possuem tal característica, o que explica o grande poder de mercado de empresas como a Microsoft. Quanto mais pessoas usam o Windows, mais softwares complementares a ele são criados, o que aumenta o valor do Windows e faz com que mais pessoas o adotem, fazendo com que mais softwares complementares sejam criados para ele, e assim sucessivamente. O efeito rede tem influência fundamental no comércio eletrônico entre empresas ou no varejo eletrônico, pois o valor dessas iniciativas pode aumentar exponencialmente na medida em que houver mais participantes negociando em rede (CATALANI et al., 2004). O exemplo a seguir ilustra esse efeito.

A empresa Acme, ${ }^{7}$ líder na área de software de gestão hospitalar, atuando na região Sul do Brasil, aproveitouse da Internet para reforçar sua posição estratégica e a sustentabilidade da sua vantagem competitiva. Ao perceber que seus clientes possuíam acesso à Internet, a empresa criou um portal B2B para congregar seus pedidos de compra e promover a interface com seus fornecedores. Com o portal, os clientes percebiam valor, ao poderem fazer suas compras automaticamente usando o sistema. Por outro lado, como a empresa já era líder de mercado na sua região, diversos fornecedores se interessaram em aderir ao portal, devido ao volume de negócios gerado. O efeito rede alcançado garantiu uma posição invejável à empresa: com o funcionamento do portal, o software hospitalar da empresa aumentou de valor, atraindo naturalmente mais clientes. Em conseqüência, novos fornecedores foram atraídos para o portal B2B, em um ciclo virtuoso que tornou a solução da empresa cada vez mais única e inatacável por concorrentes. Nesse caso, a Internet representou uma fonte de vantagem competitiva por permitir uma nova posição estratégica, defensável e valorizada.

O modelo da cadeia de valores ajuda a entender como diferentes atividades -inclusive as ligadas à TI - podem ser fonte de vantagem competitiva, na medida em que propõem uma forma de buscar listar e relacionar todas as atividades das empresas em uma framework única. Com a cadeia de valores, um gestor pode comparar a sua empresa com a concorrente e também avaliar se, internamente, suas atividades refletem o posicionamento que deseja alcançar e se tais processos são suficientemente inimitáveis (PORTER, 1999a, 1999b). De acordo com a escola de posicionamento, a vantagem competitiva é oriunda da combinação de atividades em torno de uma determinada posição que se deseja estabelecer dentro de uma indústria (PORTER, 1999a, 1999b). O instrumento da cadeia de valores é construído para a análise dessa combinação ou, nas palavras do próprio Porter, "para o exame de todas as atividades executadas por uma empresa e do modo como elas interagem [...] para a análise das fontes da vantagem competitiva." (PORTER, 1999b, p.31).

A tecnologia da informação, por permear a cadeia de valores como um todo, já que todas as atividades incluem a manipulação de informações, pode ser decisiva ao suportar a melhor consistência das atividades, colaborar para que as atividades se reforcem mutuamente e para a otimização dos esforços, inclusive, permitindo a melhor coordenação com fornecedores, canais e clientes (MALONE; YATES; BENJAMIN, 1987; PORTER; MILLAR, 1985).

A figura 2 traz uma visualização do modelo da cadeia de valores em conjunto com uma série de possíveis iniciativas de TI que podem permear toda a cadeia, permitindo a criação de elos entre processos internos e também externos, com cadeias de valores de parceiros, clientes e fornecedores.

\footnotetext{
${ }^{7}$ O nome foi propositalmente trocado, por solicitação da empresa.
} 
A matriz de intensidade da informação (PORTER; MILLAR, 1985) permite que um gestor avalie o impacto da TI na sua indústria, a partir dos vetores "intensidade de informação na cadeia de valores" e "conteúdo de informação no produto". Deve ser observado que há uma tendência de expansão do conteúdo de informação dos produtos (PORTER; MILLAR, 1985), como é o caso de carros dotados de painéis eletrônicos, computadores de bordo, suspensão e injeção de combustíveis eletrônicos, entre outras funcionalidades. Além disso, os custos decrescentes e o progresso da tecnologia estão aumentando a importância da informação no produto e na sua cadeia de valores (PORTER; MILLAR, 1985). A figura 3 traz a representação da matriz de intensidade da informação.

Figura 2 - TI na cadeia de valores

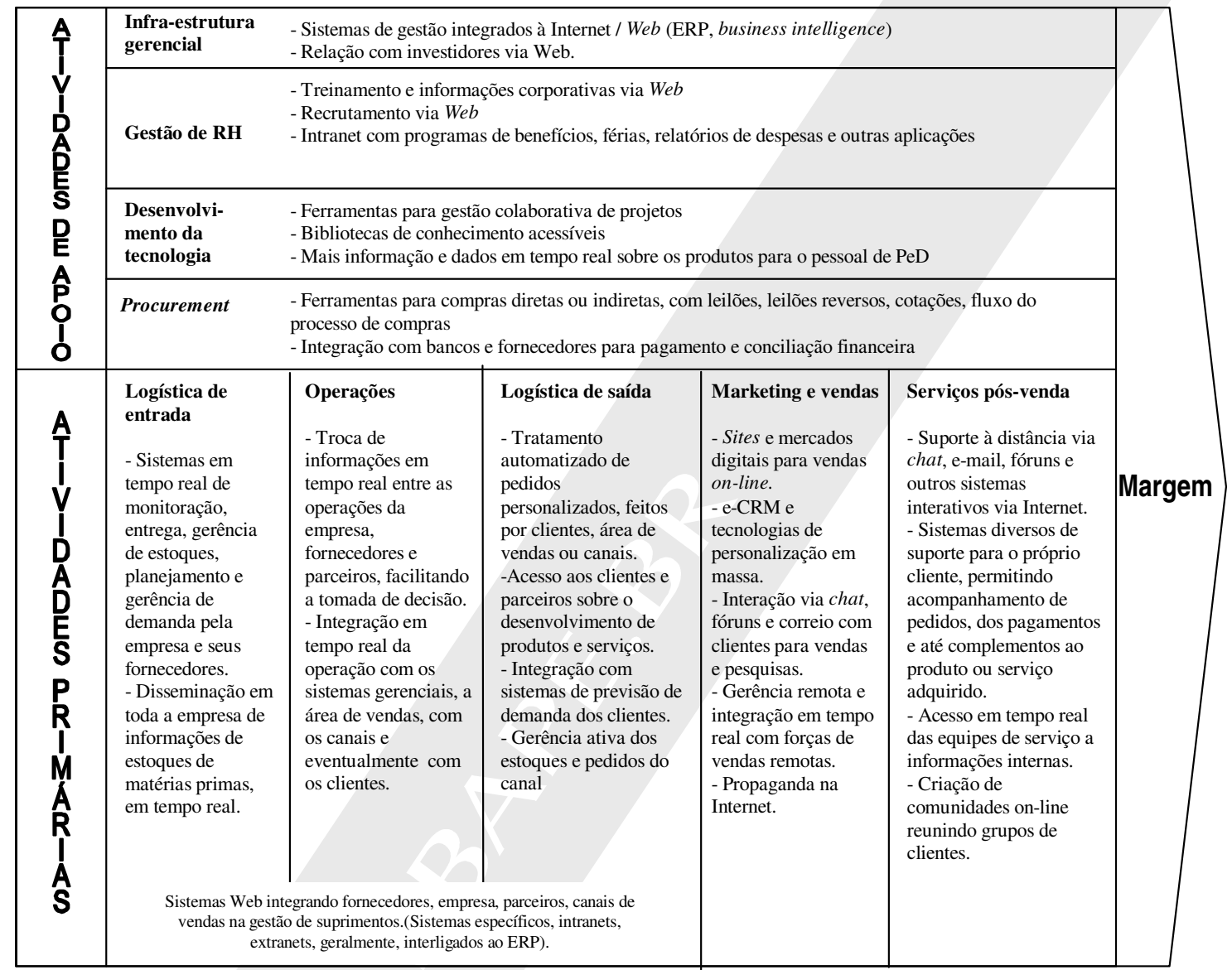

Fonte: Catalani et al (2004, p.30), Porter (2001, p.75). 


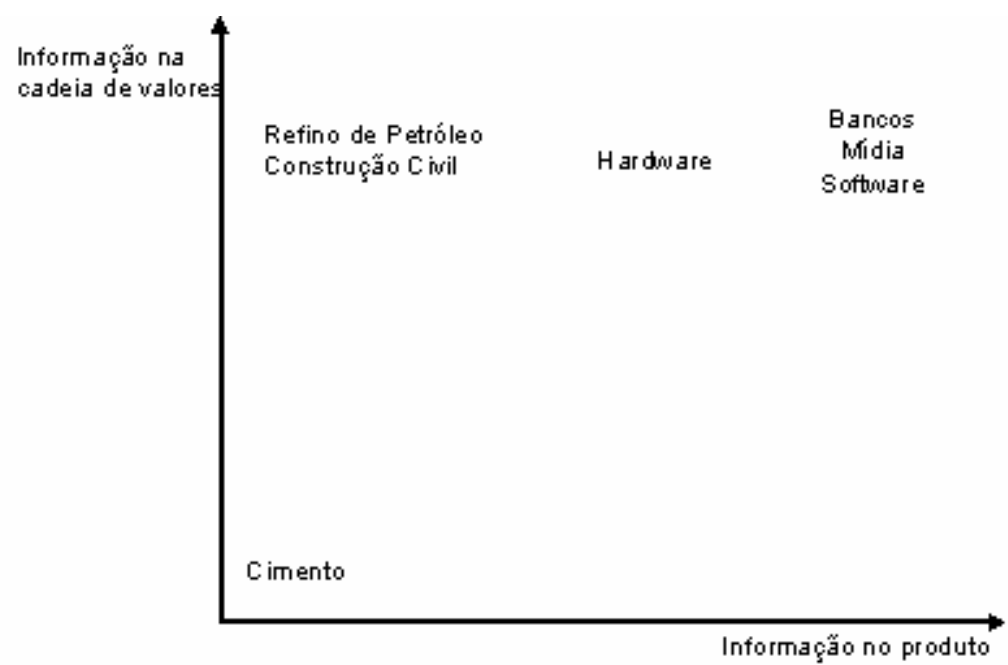

Fonte: adaptado de Porter e Millar (1985).

Em resumo, a escola de posicionamento reforça a importância de uma empresa entender a indústria em que atua e que tipo de posição estratégica deseja ocupar na mesma. Além disso, a escola também estabelece que a forma de defesa de uma determinada posição parte da combinação específica de atividades de negócios. Quanto mais específica for essa combinação e quanto mais acoplados forem esses processos, menos imitáveis eles serão, sendo portanto mais capazes de reforçar um posicionamento estratégico único dentro da indústria. Além disso, quanto mais integradas e produzindo resultados alinhados, mais essas atividades reforçarão o posicionamento estratégico desejado (PORTER, 1999a, 1999b).

Na próxima seção, será apresentada a visão estratégica do papel da TI, segundo a abordagem da escola de recursos, para, na seção seguinte, ser proposta uma integração entre as duas escolas para uma visão estratégica de TI.

\section{A visão estratégica de TI segundo a escola de recursos}

A visão da firma baseada em recursos tem influenciado a literatura de estratégia, marketing e também a literatura de TI (LADO et al, 2006; WADE; HULLAND, 2004). Segundo tal visão, a vantagem competitiva de uma firma é derivada dos recursos distintos que ela possui. Um recurso raro e valioso e de cujo valor a firma possa se apropriar é uma fonte de vantagem competitiva para essa firma (BARNEY, 1991). A vantagem competitiva torna-se sustentável se tal recurso for também inimitável, insubstituível e de baixa mobilidade (BARNEY, 1991; WADE; HULLAND, 2004).

Uma dificuldade que essa escola traz no seu bojo é a definição clara dos recursos de uma firma (GODFREY; GREGERSEN, 1999; WADE; HULLAND, 2004). Em termos genéricos, eles são apresentados como "forças que as firmas podem usar para conceber e implementar suas estratégias" (BARNEY, 1991, p.101), o que pode abranger praticamente qualquer coisa. Em abordagens de diferentes autores, recursos são apresentados de maneiras distintas, como, por exemplo, competências, habilidades, ativos ou estoques (ver WADE; HULLAND, 2004, para uma lista de autores e conceitos de recursos). Até mesmo insights sobre o mercado ou processos de negócio podem ser considerados recursos (BARNEY, 1991). Seguindo idéia original de Sanchez, Heene e Thomas (1996), Wade e Hulland (2004, p.109) consideram como mais adequada a seguinte definição de recurso: "ativos e capacidades que estão disponíveis e podem ser usados por uma organização para resposta e detecção de oportunidades e ameaças do mercado". 
Trazendo a discussão para os tipos de recursos associados à TI e adotando a tipologia proposta por Day (1994), Wade e Hulland (2004) dividem os recursos de TI em três tipos: voltados ao mercado, voltados ao ambiente interno da empresa e voltados à integração do ambiente interno com o mercado. A partir dessa taxonomia, os autores listam oito recursos típicos de TI, apresentados no quadro 2.

\section{Quadro 2 - Tipologia de recursos de TI}

\begin{tabular}{|c|c|c|}
\hline Voltados para o mercado & $\begin{array}{l}\text { Voltados para a integração } \\
\text { mercado/ambiente interno }\end{array}$ & $\begin{array}{l}\text { Voltados para o ambiente } \\
\text { interno }\end{array}$ \\
\hline $\begin{array}{l}\text { - gerenciamento de } \\
\text { relacionamentos externos } \\
\text { - capacidade de resposta ao } \\
\text { mercado }\end{array}$ & $\begin{array}{l}\text { - } \text { parcerias de negócios de TI } \\
\text { - planejamento e gerenciamento } \\
\text { da mudança de TI }\end{array}$ & $\begin{array}{l}\text { - infra-estrutura de TI } \\
\text { - habilidades técnicas de TI } \\
\text { - desenvolvimento de sistemas } \\
\text { - efetividade de custos das } \\
\text { operações de TI }\end{array}$ \\
\hline
\end{tabular}

Fonte: Wade e Hulland (2004, p.112).

Os recursos voltados para o ambiente interno são os que possuem menor potencial para gerar vantagem competitiva, por serem facilmente imitados ou adquiridos com terceiros (WADE; HULLAND, 2004). Os recursos voltados para o mercado ou para a integração entre o mercado e o ambiente interno, por outro lado, geralmente, são socialmente mais complexos, dependendo da cultura organizacional das firmas. Assim, são menos imitáveis, substituíveis ou transferíveis de uma organização para outra, significando, potencialmente, uma maior fonte de vantagem competitiva sustentável (BARNEY, 1991; WADE; HULLAND, 2004;).

A partir do recente crescimento da Internet - baseada em padrões abertos e de domínio público - e da adoção em larga escala de sistemas tipo ERP - que implementam processos gerenciais similares em diversas empresas -, a mobilidade dos recursos de TI se tornou ainda maior (PORTER, 2001). Em função disso e da acessibilidade cada vez maior dos recursos de TI, os mesmos vêm sendo apontados como não-estratégicos (CARR, 2003). Em resposta a isso, a literatura que segue a escola de recursos tem se voltado à investigação de fatores que complementem ou moderem o impacto estratégico dos recursos de TI (MELVILLE; KRAEMER; GURBAXANI, 2004; TIPPINS; SOHL, 2003; WADE; HULLAND, 2004). Noutras palavras, investiga-se que outros recursos, de forma complementar ou moderadora, colaboram ou inibem o impacto estratégico dos recursos de TI.

Para Wade e Hulland (2004), a literatura nesse sentido é ainda insuficiente diante dos apelos conceituais e empíricos existentes. Conceitualmente, como TI é, quase sempre, uma tecnologia de apoio, faz sentido investigar os recursos de TI em conjunto com outros. Empiricamente, tem sido forte a evidência de que há recursos complementares aos de TI, isto é, recursos cuja presença é decisiva para que os recursos de TI gerem vantagem competitiva, como demonstram autores como:

- Powel e Dent-Micallef (1997): que mostraram que o uso complementar de TI e recursos humanos leva as firmas a uma performance superior;

- Reich e Kaarst-Brown (1999): que mostraram que o alinhamento estratégico de TI com o negócio depende fortemente do conhecimento sobre TI estar disseminado na empresa;

- Tippins e Sohl (2003): que propõem e testam empiricamente a idéia de que a capacidade de aprendizado organizacional influencia fortemente o aproveitamento dos recursos de TI por parte de uma empresa; e

- Melville, Kraemer e Guarbaxani (2004): que propõem um modelo em que os recursos de TI, juntamente com os recursos humanos de TI e recursos complementares da organização, integrem processos de negócios que possam gerar uma melhor performance organizacional.

Os recursos que poderiam ser qualificados como moderadores do impacto estratégico da TI podem ser tanto de ordem organizacional quanto ambiental (WADE; HULLAND, 2004). Entre os de natureza organizacional, um dos mais mencionados na literatura é o comprometimento da alta gerência da organização. O impacto potencial 
de sistemas de TI implementados com baixo ou nenhum comprometimento da alta gerência é muito baixo, já que suas implementações tanto ficam incompletas quanto o potencial estratégico das informações não é totalmente aproveitado (POWELL; DENT-MICALLEF, 1997; ROSS; BEATH; GOODHUE, 1996; WADE; HULLAND, 2004). De forma análoga a essa literatura, Mata e Fuerst (1995) concluem que a habilidade gerencial de TI é um fator decisivo para a TI ser uma fonte de vantagem competitiva sustentável. Por outro lado, outros fatores organizacionais, como a cultura da empresa ou o tamanho das firmas ainda não foram objeto de uma quantidade relevante de pesquisa (WADE; HULLAND, 2004).

Os fatores ambientais que poderiam afetar o impacto estratégico de recursos de TI são o grau de estabilidade do ambiente, a intensidade da competição e a complexidade do ambiente (WADE; HULLAND, 2004). Em ambientes instáveis, os recursos de TI mais voltados para o mercado ou para a integração entre mercado e ambiente interno terão mais valor do que aqueles focados no ambiente interno, pois permitem uma maior adaptabilidade à empresa que os possuir. Em ambientes nos quais a competição é muito acirrada - como em indústrias declinantes -, os recursos de TI mais voltados ao ambiente interno serão mais relevantes, pois são os mais ligados à eficiência operacional. Em mercados muito complexos, recursos de TI dos três tipos (ver quadro 2) possuem relevância estratégica similar, pois a própria compreensão, para um concorrente, do que deve ser copiado, é muito difícil (WADE; HULLAND, 2004).

Melville, Kraemer e Gurbaxani (2004) propõem um modelo abrangente, dentro do qual o processo de geração de valor de recursos de TI está ligado a outros recursos e a questões ambientais, tal como discutido anteriormente. A figura 4, com pequenas adaptações, reproduz tal modelo, o qual ilustra bem a visão estratégica de TI segundo a escola de recursos.

De acordo com o modelo de Melville, Kraemer e Gurbaxani (2004), a geração de valor de negócios a partir de TI se dá dentro do ambiente da organização, sendo influenciada tanto pelo ambiente competitivo quanto pelo macroambiente. O macroambiente representa questões amplas, como as características do país no qual a organização está inserida. $\mathrm{O}$ ambiente competitivo traz à tona questões relativas à indústria na qual a organização está inserida, a qual pode ser mais ou menos instável, de competição mais ou menos intensa, de maior ou menor complexidade, envolvendo ou não recursos de parceiros. A discussão pregressa nessa seção exemplifica esse ponto. Como já dito, em um ambiente de competição mais intensa, certos recursos de TI - aqueles mais voltados à performance interna - se tornam mais relevantes, estrategicamente, tendo maior chance de gerar valor para a organização.

Figura 4 - A geração de valor a partir de recursos de TI

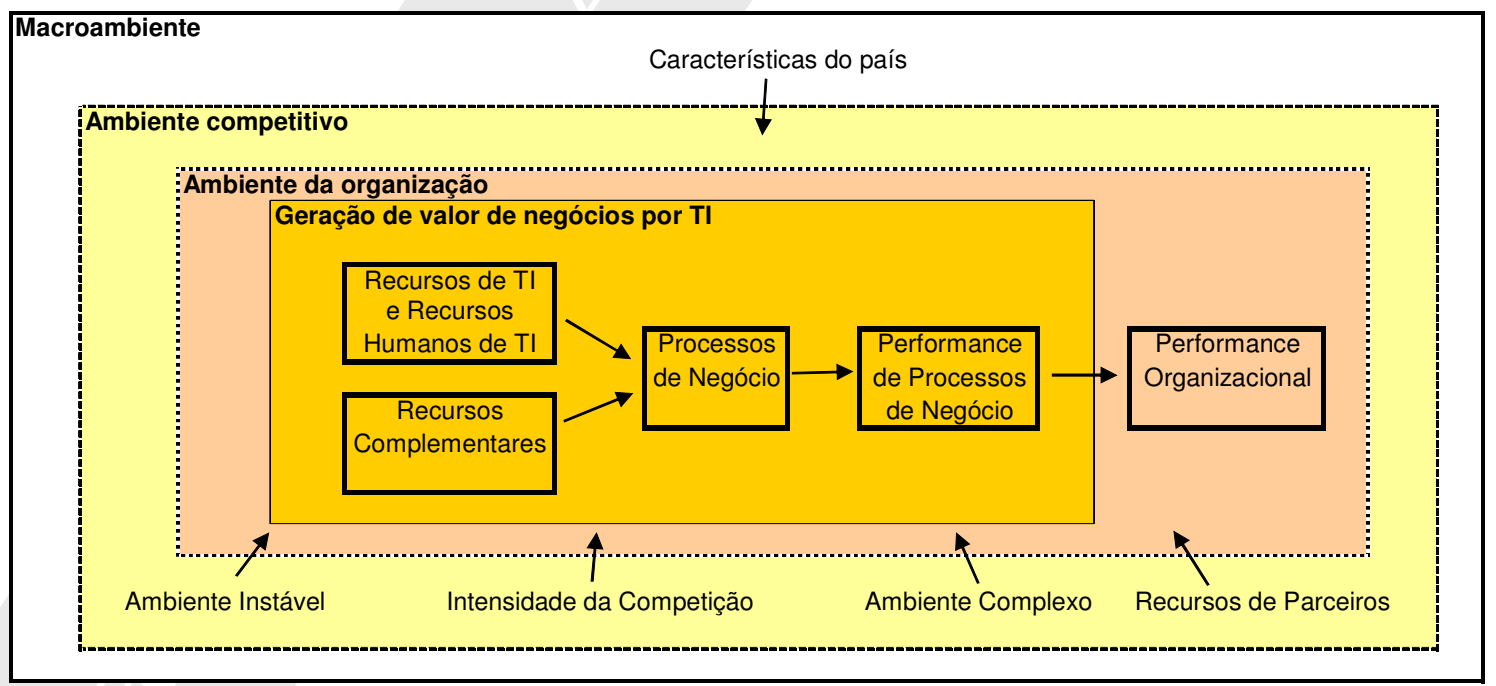

Fonte: adaptado de Melville, Kraemer e Gurbaxani (2004).

Dentro do ambiente organizacional, Melville, Kraemer e Gurbaxani (2004) argumentam que a geração de valor por parte de recursos de TI depende de uma combinação de recursos de TI (software, hardware, infra-estrutura 
de TI e sistemas presentes na organização) com recursos humanos de TI (habilidades técnicas e gerenciais na área de TI). Além disso, outros recursos complementares (como capital e outros recursos humanos, que não os de TI) também influenciam no impacto que os recursos de TI terão nos processos da organização e na performance de tais processos. O impacto final dependerá, além disso, das características do ambiente competitivo e do macroambiente (MELVILLE; KRAEMER; GURBAXANI, 2004).

Em suma, a literatura que estuda o impacto estratégico da TI nas organizações a partir da escola estratégica de recursos é emergente e ainda permanece com algumas fronteiras em aberto (MELVILLE; KRAEMER; GURBAXANI, 2004; WADE; HULLAND, 2004). O modelo integrativo de Melville, Kraemer e Gurbaxani (2004) é um avanço importante, na medida em que reúne perspectivas de diversos outros autores e evidencia a importância dos recursos complementares e a influência do ambiente externo à organização na geração de valor por parte de recursos de TI.

\section{Articulando as escolas de pensamento estratégico a partir da TI: proposições}

à primeira vista, há grande distância entre as escolas estratégicas de recursos e de posicionamento. Enquanto para a primeira, a vantagem competitiva advém da posse de recursos valiosos, raros, inimitáveis e insubstituíveis (BARNEY, 1991), para a segunda, a vantagem competitiva seria derivada de uma posição de mercado específica que uma firma ocupa, a qual seria alcançada por meio de uma combinação singular de atividades (PORTER, 1999a).

Apesar de, conceitualmente, as duas escolas estratégicas aparentarem ser contraditórias, em artigo fundamental para a recente literatura da escola estratégica de recursos, Barney (1991) explicitamente argumenta acerca da integração da sua visão com a da escola de posicionamento:

Em seu trabalho recente, Porter introduziu o conceito de cadeia de valores para ajudar gerentes a isolarem vantagens baseadas em recursos para suas firmas. A visão da firma baseada em recursos aqui desenvolvida, simplesmente, leva adiante a lógica da cadeia de valores, examinando os atributos que recursos isolados pela análise da cadeia de valores devem possuir para serem fontes de vantagem competitiva sustentável. (BARNEY, 1991, p.105, tradução dos autores)

Além de fazer a ligação entre a visão da escola de recursos e o conceito da cadeia de valores, Barney (1991) também argumenta que os modelos de estratégia que denomina de ambientais são úteis para "isolar os atributos das firmas que exploram oportunidades ou neutralizam ameaças", ajudando a identificar quais recursos são valiosos ou não. Porém, o autor não chega a aprofundar a relação entre as duas escolas de pensamento estratégico, sequer mencionando a questão do posicionamento.

A partir de análise teórica dos conceitos anteriormente apresentados, essa seção busca a articulação das duas escolas, através da formulação de quatro proposições a respeito, detalhadas a seguir.

\section{$O$ valor do posicionamento}

As duas escolas possuem preocupações comuns acerca do que seja vantagem competitiva, como reconhecido pelo próprio Barney (BARNEY, 1991). Nos dois casos, defende-se a vantagem competitiva sustentável (BARNEY, 1991; PORTER, 1999a). Nas duas escolas, há a preocupação de uma determinada empresa possuir os meios para criar uma situação valiosa e de difícil imitação por parte de seus concorrentes (BARNEY, 1991; PORTER, 1999a). Nas duas escolas, há a preocupação com a sustentabilidade dessa situação. Há, contudo, uma diferença quanto aos meios para tanto: recursos valiosos e exclusivos em uma escola (Barney, 1991); uma combinação de atividades singular, reforçando um posicionamento, na outra (Porter, 1999a).

Num primeiro passo para a articulação das duas visões, é preciso considerar-se a questão da indústria e a importância do conceito de posicionamento. A escola de Porter, quando enfoca a questão do posicionamento, utiliza como unidade de análise a indústria, a qual analisa através do modelo das cinco forças. 
Embora a escola de recursos adote a firma como unidade de análise principal (DYER; SINGH, 1998), ao estudar a importância estratégica de recursos de TI, não ignora a influência da indústria e dos movimentos de mercado na estratégia da firma, como mostram o modelo de Melville, Kraemer e Gurbaxani (2004), apresentado na seção "A visão estratégica de TI segundo a escola de posicionamento", e a revisão da literatura de Wade e Hulland (2004). Esses autores, em particular, argumentam que os recursos de TI ligados à relação da organização com o ambiente externo têm "um impacto mais duradouro na posição competitiva de longo prazo do que os recursos de TI ligados somente ao ambiente interno." (Id, p.122).

Além disso, o adequado entendimento da indústria e do desenvolvimento do posicionamento estratégico é especialmente relevante quando se estuda o papel da TI, pois ele permite novas oportunidades de coordenação ao longo da cadeia produtiva (MALONE; YATES; BENJAMIN, 1987) e apresenta novas ameaças e oportunidades, as quais podem ter impacto fundamental quando ligadas à exploração de situações de efeito rede (VARIAN; SHAPIRO, 1999)(ver quadro 1).

Ao propor a análise da indústria - e o correspondente modelo das cinco forças - como passo fundamental para o entendimento do ambiente no qual a firma está inserida, a escola de posicionamento oferece um mecanismo de consideração sistemático sobre os diferentes aspectos envolvidos na ambiência na qual está inserida uma organização (PORTER, 1986). Além disso, a análise da indústria permite a análise de diferentes alternativas de posicionamento estratégico dentro de uma determinada indústria (PORTER, 1986).

Portanto, a proposição 1, a primeira que procura articular as duas escolas sob o contexto de TI, sintetiza os argumentos expostos anteriormente: ${ }^{8}$

Proposição 1: "Considerando que os recursos de TI de uma organização são aplicados, freqüentemente, na sua relação com o ambiente externo, permitindo inclusive diferentes formas de coordenação da cadeia produtiva, a análise da atratividade de uma indústria é fundamental para a avaliação do impacto estratégico da utilização de recursos de TI nas organizações pertencentes a essa indústria." (BARNEY, 1991; MALONE, 1987; PORTER, 1999a, 2001; MELVILLE; KRAEMER; GURBAXANI, 2004; WADE; HULLAND, 2004)

Outra questão importante onde o conceito do posicionamento estratégico é útil, diz respeito ao entendimento do que é valioso e do que não o é para uma determinada organização. Diferentes organizações, mesmo atuando em uma mesma indústria, poderão atribuir valores diferentes a recursos de TI similares. Por exemplo: para uma companhia aérea de baixo custo, que opte por não possuir lojas físicas, um sistema de vendas via Internet terá um valor altíssimo. Por outro lado, para outra companhia aérea, que atue com posicionamento estratégico de diferenciação e com uma grande cadeia de lojas de atendimento diferenciado, o mesmo sistema de vendas via Internet terá um valor muito mais baixo. Dessa forma, chega-se a uma segunda proposição de articulação entre as escolas, baseada no fato de que a escolha do posicionamento estratégico de uma firma implica a determinação de quais diferentes recursos serão mais ou menos valiosos para a mesma, na medida em que reforcem ou não um determinado posicionamento adotado por ela: ${ }^{6}$

Proposição 2: o valor dos recursos de TI - entre uma infinidade de recursos que poderiam ser utilizados por uma firma - muda em função do contexto da indústria onde a firma está inserida e do posicionamento pretendido pela mesma (BARNEY, 1991; PORTER, 1999a, 1999b).

Por fim, a análise da indústria e a utilização do instrumento do modelo das cinco forças tem um último valor adicional. Embora a escola de recursos compreenda que os recursos que conferem vantagem competitiva são aqueles valiosos e de cujo valor a firma consegue se apropriar (AMIT; SHOEMAKER, 1993; COLLIS; MONTGOMERY, 1995; GRANT, 1991; WADE; HULLAND, 2004), não foi encontrado, na literatura ligada a recursos de TI, um estudo sistemático sobre em que situações uma organização seria capaz ou não dessa apropriação do valor gerado. No quadro 3, a questão da apropriação do valor gerado por recursos de TI é aprofundada e exemplificada.

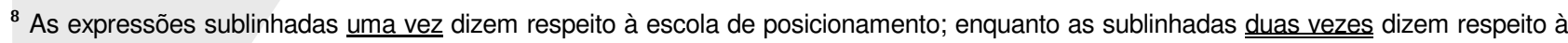
escola de recursos.
} 


\section{Quadro 3}

\section{Os recursos de TI e a apropriação do seu valor}

Embora seja reconhecida como importante por diversos autores (AMIT; SHOEMAKER, 1993; COLLIS; MONTGOMERY, 1995; GRANT, 1991; WADE; HULLAND, 2004), a questão de quem se apropria do valor gerado por um recurso de TI é pouco estudada na literatura de RBV aplicada à TI. A questão não é citada em diversos artigos da área, como, por exemplo, Melville, Kraemer e Gurbaxani. (2004), Tippins e Sohl (2003) e King e Zeithaml (2003). Não é difícil imaginar situações em que a posse de recursos valiosos e raros não, necessariamente, gere valor para as empresas por elas não poderem se apropriar do valor gerado. Por exemplo, Wade e Hulland (2004) sugerem que a presença de técnicos de TI com capacitação acima da média pode não significar uma vantagem competitiva se os salários também forem acima da média, caso em que os próprios técnicos é que poderiam estar absorvendo totalmente a vantagem competitiva.

Outros cenários em que concorrentes ou clientes absorvam o valor gerado também poderiam ser imaginados. Por exemplo, na implantação de processos e sistemas de integração das logísticas de duas empresas (com sistemas de supply-chain management), supondo que seja gerado valor (por exemplo, pela otimização de estoques), não é automática a divisão de tal valor entre fornecedor e cliente. Em geral, essa determinação de como o valor gerado será repartido advém do poder de barganha relativo de cada um no mercado, mas também pode advir da liderança do processo de implantação do sistema de TI.

Por exemplo, em um estudo de caso na indústria do vestuário, Lee, Farhoomand e Ho (2004) mostram como a TAL Apparel Limited se utilizou da liderança no processo de implantação do sistema de TI para ganhar vantagem competitiva, apesar de ser a parte mais fraca da cadeia de suprimentos em que estava inserida, isto é, de não ser a parte com o maior poder de barganha.

$\mathrm{Na}$ área de TI, onde os principais recursos que potencialmente gerariam vantagem competitiva são ligados à integração entre as firmas (WADE; HULLAND, 2004), entender como as diferentes partes envolvidas interagem e quem efetivamente se apropria dos benefícios gerados - clientes, fornecedores e a própria organização - pela utilização dos recursos de TI, é de fundamental relevância. A escola de posicionamento, através da análise da indústria, traz à tona a questão do poder de barganha relativo dos membros da cadeia produtiva, facilitando o entendimento de quem deverá se apropriar do valor gerado por diferentes recursos.

Assim, chega-se à terceira proposição para articulação entre as duas escolas: ${ }^{6}$

Proposição 3: "A avaliação da capacidade de uma firma se apropriar do valor gerado por um recurso de TI deve ser realizada através da análise de atratividade da indústria onde está inserida, a qual permite a investigação do poder de barganha relativo das diferentes organizações envolvidas na utilização de um recurso de TI." (AMIT; SHOEMAKER, 1993; COLLIS; MONTGOMERY, 1995; GRANT, 1991; PORTER, 2001; WADE; HULLAND, 2004)

\section{A questão da combinação de recursos e atividades}

A escola de posicionamento afirma que a vantagem competitiva tem origem em uma combinação única das diversas atividades dentro de uma empresa, de forma que elas sejam consistentes (e não contraditórias), que elas se reforcem mutuamente e que permitam a otimização de esforços dentro da firma (PORTER, 1999a). Embora a escola de recursos não cite esse mesmo tipo de combinação, ela estabelece, inclusive, de forma empírica, que o valor de um recurso depende da maior ou menor presença de outros recursos nas empresas (MELVILLE; KRAEMER; GURBAXANI, 2004; POWEL; DENT-MICALLEF, 1997; TIPPINS; SOHL, 2003). Em especial, o modelo de Melville, Kraemer e Gurbaxani (2004), descrito na seção "A visão estratégica de TI segundo a escola de posicionamento", mostra claramente que o valor final dos recursos de TI depende da sua interação com recursos humanos de TI e com outros recursos complementares dentro da firma.

Os conceitos utilizados pelas duas escolas guardam relação clara. Para a escola de recursos, o valor de um determinado recurso de TI para uma firma depende da sua combinação com outros recursos e atividades, que podem ou não ser de TI. Por exemplo, Barney (1991) afirma que se, por um lado, 
estratégias que explorem apenas computadores são fáceis de ser imitadas e, portanto, não são uma fonte de vantagem competitiva sustentável [...], por outro lado, sistemas que são profundamente associados aos processos gerenciais de uma firma podem ter potencial de vantagem competitiva sustentável. (BARNEY, 1991, p.114)

Melville, Kraemer e Gurbaxani (2004) são ainda mais explícitos:

outros recursos organizacionais, como as práticas no ambiente de trabalho, interagem com (os recursos de) TI, tanto como mediadores quanto como moderadores para a efetivação de impactos no desempenho organizacional (a partir dos recursos de TI). (MELVILLE; KRAEMER; GURBAXANI, 2004, p.292)

Para a escola de posicionamento, "estratégia é criar uma posição exclusiva e valiosa, envolvendo um diferente conjunto de atividades." (PORTER, 1999a, p.63). A informação está presente em todas as atividades e, portanto, os recursos de TI têm possibilidade de influenciar na cadeia de valores como um todo e, em especial, na forma como os processos são interligados (PORTER, 2001; PORTER; MILLAR, 1985). O valor estratégico da tecnologia da informação será tanto maior quanto mais os recursos de TI estiverem relacionados a outras atividades da organização, de forma única e em reforço ao posicionamento almejado (PORTER, 1999a, 2001). No quadro 4, é apresentado, em cima de um mesmo exemplo, a clara relação entre as afirmativas das duas escolas.

\section{Quadro 4 \\ Recursos ou atividades complementares}

Para ilustrar a relação entre os conceitos utilizados pelas duas escolas, será apresentado um exemplo simples, primeiramente, nos termos da escola de recursos e, em um segundo momento, nos termos da escola de atividades/posicionamento.

Para uma companhia aérea, o valor gerado pela utilização de um sistema de vendas via Internet (um recurso de TI) depende dos recursos complementares disponíveis na empresa. Por exemplo, o sistema de vendas terá um valor muito baixo se não for acompanhado de capacitação para os atendentes de aeroporto (um recurso complementar). Se, por exemplo, os atendentes de aeroporto não estiverem bem treinados em como lidar com o passageiro que tiver comprado seu bilhete via Internet e o direcionarem para a loja física do aeroporto, certamente, o valor da iniciativa de venda on-line se dissipará em meio à insatisfação do cliente e aos custos de tal loja física prestar esse atendimento.

o mesmo exemplo pode ser dado nos termos da escola de posicionamento. Para uma companhia a aérea, o valor gerado a partir da implantação de um processo de vendas via Internet depende da implantação de processos complementares. Por exemplo, se não houver um processo de capacitação para os atendentes de aeroporto a respeito do novo sistema de vendas, o atendimento aos clientes no aeroporto não será compatível com o novo processo de vendas via Internet, reduzindo o valor desse investimento.

O exemplo do quadro 4 mostra que a escola de recursos, ao sugerir que os recursos de TI, para gerarem valor, devam ser acompanhados de outros recursos, no fundo faz uma afirmação muito próxima da escola de posicionamento, que preconiza o encadeamento e o acoplamento entre todas as atividades presentes na cadeia de valores de uma organização. Os recursos de TI, da primeira escola, são as atividades relacionados a TI da segunda escola. A complementaridade da primeira equivale ao encadeamento/acoplamento de atividades da segunda.

Como já dito, o modelo da cadeia de valor, preconizado pela escola de posicionamento, é uma forma analítica e sistemática de avaliação do grau de combinação das atividades de uma firma. Utilizando-o, é possível o entendimento de quais recursos devem ser combinados para que a geração de valor dentro de uma firma seja a máxima possível, bem como se há coerência entre as diferentes atividades e o posicionamento pretendido pela firma dentro da sua indústria.

Assim, pode-se inferir a proposição $4:^{6}$ 
Proposição 4: "A geração de valor a partir de recursos de TI depende da presença de outros recursos complementares. O desenvolvimento de relações de complementaridade reforça a complexidade da sua utilização, diminuindo as chances de imitação e aumentando as chances de se obter vantagem competitiva sustentável. Assim, o instrumento da cadeia de valores, ao permitir que se avalie a implementação de combinações de recursos de TI sistemicamente integrados e ligados a outros recursos, aumenta o entendimento sobre o impacto estratégico dos recursos de TI." (BARNEY, 1991; MELVILLE; KRAEMER; GURBAXANI, 2004; PORTER, 1985, 1999a; WADE; HULLAND, 2004)

Nesta seção, foram apresentadas quatro proposições que promovem, a partir da análise dos recursos de TI, a articulação entre as escolas de estratégia de recursos e de posicionamento.

Na primeira proposição, sugere-se que os recursos de TI, por freqüentemente estarem na fronteira entre a organização e o ambiente externo e terem potencial de alterar significativamente a coordenação de tal ambiente, devem ser analisados à luz da análise da indústria.

A segunda proposição sugere que, para diferentes posicionamentos estratégicos de uma firma em uma indústria, o valor de um mesmo recurso de TI pode ser diferente, só sendo possível determinar seu impacto estratégico à luz do contexto competitivo da indústria em questão e do posicionamento pretendido pela firma.

A terceira proposição aponta para o fato de que os recursos de TI, por estarem na fronteira entre a organização e o ambiente externo, podem ter seu valor apropriado por diferentes partes em uma indústria, sendo necessária uma análise dos poderes de barganha relativos entre fornecedores, parceiros e concorrentes para o correto entendimento dessa divisão de valor estratégico.

Por fim, a quarta proposição sugere que a análise da cadeia de valores pode ser um instrumento relevante para a estruturação de complementaridade de recursos, aumentando o seu valor estratégico.

Na próxima seção, são apresentadas as observações finais dos autores, as implicações deste trabalho para pesquisa futura e para a prática gerencial, bem como as limitações deste artigo.

\section{Observações finais, contribuições para pesquisa futura e prática gerencial e as limitações do artigo}

Neste artigo, mostra-se, tendo a TI como elemento articulador, que é possível construir pontes de articulação entre a escola estratégica de recursos e a escola estratégica de posicionamento.

A visão da escola de recursos, ao deixar claro quais atributos tornam um determinado recurso estratégico (BARNEY, 1991, 1995), facilita a tomada de decisão para o gestor de TI. Entretanto, tendo em vista as particularidades dos recursos de TI - fortemente ligados à relação da organização com o ambiente externo e cujo valor estratégico depende de outros recursos complementares -, a abordagem da escola de recursos é insuficiente para, sozinha, determinar em quais recursos uma organização deve investir. As proposições construídas neste artigo, as quais visam integrar a abordagem da escola de recursos com a da escola de posicionamento, são uma provável solução para tal problema.

Para gestores, as proposições apresentadas neste artigo, se consideradas simultaneamente, podem ajudar na tomada de decisão em relação a projetos de investimentos em TI, aumentando as chances de tais projetos gerarem valor estratégico para as suas organizações. Sem perder o entendimento de quais atributos tornam um determinado recurso de TI estrategicamente relevante - contribuição da escola de recursos - o gestor poderá, usando as proposições apresentadas:

- identificar como tal recurso de TI implica ou é impactado por reorganizações na indústria em que sua organização está inserida (proposição 1);

- avaliar, tendo em vista o posicionamento estratégico da sua organização, qual o efetivo valor de tal recurso de TI (proposição 2); 
- ponderar o poder de barganha relativo das várias partes envolvidas na implementação de tal recurso de TI, avaliando a capacidade de sua organização apropriar-se ou não do valor gerado por ele (proposição 3); e

- projetar e avaliar relações complementares entre tal recurso de TI e outros recursos, aumentando a possibilidade de tal recurso gerar vantagem competitiva para a sua organização (proposição 4).

Para a academia, as proposições desenvolvidas - especialmente por comporem uma proposta de integração entre escolas de pensamento estratégico que, em geral, são apresentadas como contraditórias - geram possibilidades de investigação futura, especialmente, por terem que ser testadas e validadas cientificamente.

A pesquisa foi orientada pela literatura relativa a recursos de TI. Para a área de marketing, com uma abordagem diferente, Hooley, Broderick e Möller (1998) também desenvolveram esforços para integrar a visão do posicionamento com o da RBV. Assim, uma vertente relevante para pesquisa futura é a verificação da validade das proposições articuladoras, aqui desenvolvidas para recursos de TI, para outros tipos de recursos.

Por fim, para a academia, esta pesquisa também visa gerar progresso no debate crítico que vem sendo travado em torno da visão da firma baseada em recursos. Autores como Priem e Butler (2001a, 2001b), Lado et al. (2006), Fahy (2000) e o próprio Barney (2001), entre outros, têm discutido o quanto a abordagem da RBV é realmente aplicável e relevante, não apenas para o entendimento dos determinantes de vantagens competitivas, como também para a prática gerencial associada. Ao propor novas proposições, aplicáveis à análise de recursos de TI, que integram a abordagem da RBV à da escola de posicionamento, esta pesquisa pode ser vista como facilitadora do aproveitamento das idéias da RBV na elaboração teórica e na prática gerencial.

Esta pesquisa ambicionou integrar duas escolas de pensamento estratégico de forma analítico-teórica e não empírica, o que limita a validade das suas conclusões. A pesquisa foi construída apenas sob a ótica dos recursos de TI, o que limita seus resultados à articulação das duas escolas apenas em relação a tal tipo de recursos. Além disso, a própria análise é limitada pelo investimento de tempo e recursos que puderam ser utilizados. Essa pesquisa deve ser considerada uma pesquisa em andamento, que certamente poderá ser refinada, não apenas com uma extensão empírica, mas também com um, ainda maior, aprofundamento teórico. 


\section{Referências}

AMIT, R.; SHOEMAKER, P. J. H. Strategic assets and organizational rent. Strategic Management Journal, v.14, p.33-46, 1993.

ANDERSON, M; BANKER, R.; RAVINDRAN, S. The new productivity paradox. Communications of the ACM, v.46 ,n.3, Mar. 2003.

BARNEY, J. Firm resources and sustained competitive advantage. Journal of Management, v.17, n.1, p.99-120, 1991.

. Looking inside for competitive advantage. The Academy of Management Executive, v.9, n.4, Nov. 1995.

Is the resource-based "view" a useful perspective for strategic management research? Yes. Academy of Management Review, v.26, n.1, p.41-56, 2001.

BRYNJOLFSSON, E.; HIT, L. Computing productivity: firm-level evidence. MIT Sloan Working Paper, n.4210-01, June 2003.

CARR, N. G. It doesn't matter. Harvard Business Review, May 2003.

CATALANI, L. et al. E-commerce. Rio de Janeiro: Editora FGV, 2004.

COLLIS, D. J.; MONTGOMERY, C. A. Competing on resources: strategy in the 1990s. Harvard Business Review, v.73, n.4, p.118-128, 1995.

DAY, G. The capabilities of market-driven organizations. Journal of Marketing, v.58, n.4, p.37-52, 1994.

DEDRICK, J; GURBAXANI, V.; KRAEMER, K. Information technology and economic performance: a critical review of the empirical evidence. ACM Computing Surveys (CSUR), v.35, Issue 1, p.1-28, Mar. 2003.

DYER, J. H.; SINGH, H. The relational view: cooperative strategy and sources of interorganizational competitive advantage. Academy of Management Review, v.23, n.4, p.660-679, 1998.

EVANS P. B.; WURSTER T. S. Getting real about virtual commerce. Harvard Business Review, v.77, n.6, p.84-94, 1999.

FAHY, J. The resource-based view of the firm: some stumbling-blocks on the road to understanding sustainable competitive advantage. Journal of European Industrial Training, v.24, p.94-104, 2000.

GODFREY, P. C.; GREGERSEN, H. B. Where do resources come from? A model of resource generation. The Journal of High Technology Management Research, v.10, n.1, p.37-60, 1999.

GRANT, R. M. The resource-based theory of competitive advantage: implications for strategy formulation. California Management Review, v.33, n.1, p.114-135, 1991.

HOONEY, G.; BRODERICK, A.; MÖLLER, K. Competitive positioning and the resource-based view of the firm. Journal of Strategic Marketing, v.6, p.97-115, 1998.

JOIA, L. A.; FERREIRA, S. Modelo de negócios: construto real ou metáfora de estratégia? Cadernos Ebape.BR, v.3, n.4, Dez. 2005.

KAPLAN, B.; MAXWELL, J. A. Qualitative research methods for evaluating computer information systems. In: ANDERSON, J. G.; AYDIN, C. E.; JAY, S. J. (Ed.). Evaluating health care information systems: methods and applications. Thousand Oaks: Sage, p.45-68, 1994.

KING, A. W.; ZEITHAML. Measuring organizational knowledge: a conceptual and methodological framework. Strategic Management Journal, v.24, n.8, p.763-772, Aug. 2003.

KLEIN, H. K.; MYERS, M. D. A set of principles for conducting and evaluating interpretive field studies in information systems. MIS Quarterly, v.23, p.67-96, 1999.

LADO, A et al. Paradox and theorizing within the resource-based view. Academy of Management Review, v.31, n.1, p.115-131, 2006.

LAUDAUER, T. The trouble with computers: usefulness, usability and productivity. [S.I.]: The MIT Press, 1995.

LAURINDO F. et al. 0 papel da tecnologia da informação (TI) na estratégia das organizações. Gestão e Produção, v.8, n.2, p.160-179, ago. 2001.

LEE, H.; FARHOOMAND, A.; HO, P. Innovation through supply chain reconfiguration. MIS Quarterly Executive, v.3, n.3, Sep. 2004.

MALHOTRA, N. K. Pesquisa de Marketing - uma orientação aplicada. 3 ed. Porto Alegre: Bookman, 2001.

MALONE, T. W.; YATES, J.; BENJAMIN, R. I. Electronic markets and hierarchies. Communications of the ACM, v.30, n.6, p.484-497, June 1987. 
MATA, F. J.; FUERST, W. L. Information technology and sustained competitive advantage: a resource-based analysis. MIS Quarterly, p.487505, Dec. 1995

MEIRELLES, F. S. Informática nas empresas: perfil, indicadores, gastos e investimentos. In: RUBEN, G., WAINER, J.; DWYER, T. (Org.). Informática, organizações e sociedade no Brasil. São Paulo: Cortez, 2003.

MELVILLE, N., KRAEMER, K.; GURBAXANI, V. Review: information technology and organizational performance: an integrative model of IT business value. MIS Quarterly, v.28, n.2, p.283-322, 2004.

MINTZBERG, H., AHLSTRAND, B.; LAMPEL, J. Strategy safari - a guided tour through the wilds of strategic management. New York: The Free Press, 1998.

OSEY-BRYSON, K.; KO, M. Exploring the relationship between information technology investments and firm performance using regression splines analysis. Information and Management, v.42, p.1-13, 2004.

PATON, M. Qualitative evaluation and research methods. 2nd ed. Newbury Park: Sage, 1990.

PENROSE, E. T. The theory of the growth of the firm. New York: John Wiley \& Sons, 1959.

PORTER, M. E. Estratégia competitiva. 7.ed. Rio de Janeiro: Campus, 1986.

0 que é estratégia? In: PORTER, M. E. Competição: estratégias competitivas essenciais. 7. ed. Rio de Janeiro: Campus, 1999 a. Vantagem competitiva. 18.ed. Rio de Janeiro: Campus, 1999b.

Strategy and the Internet. Harvard Business Review, Mar. 2001.

; MILLAR, V. E. How information gives you competitive advantage. Harvard Business Review, July 1985.

POWELL, T. C.; DENT-MICALLEF, A. Information technology as competitive advantage: the role of human, business, and technology resources. Strategic management Journal, v.18, n.5, p.375-405, 1997.

PRIEM, R. L.; BUTLER, J. E. Is the resource-based "view" a useful perspective for strategic management research? Academy of Management Review, v.26, n.1, p.22-40, 2001a.

E. Tautology in the resource-based view and implications of externally determined resource value: further comments. Academy of Management Review, v.26, n.1, p.57-65, 2001 b.

REICH, B. H.; KAARST-BROWN. Seeding the line. MIS Quarterly, v.23, n.3, p.337-364, Sep. 1999.

ROSS, J. W.; BEATH, C. M.; GOODHUE, D. L. Develop long-term competitiveness through IT Assets. Sloan Management Review, v.38, n.1, p.31-42, 1996.

SANCHEZ, R; HEENE, A.; THOMAS, H. Introduction: towards the theory and practice of competence-based competition. Oxford: Pergamon Press, 1996.

STRASSMAN, P. A. The business value of computers: an executive's guide. New Canaan: Information Economics Press, 1990.

TIPPINS, M. J.; SOHL, R. S. IT competency and firm performance: is organizational learning a missing link? Strategic Management Journal, v.24, p.745-761, 2003.

VARIAN, H. R.; SHAPIRO, C. Information rules - a strategic guide to the network economy. Boston: Harvard Business School Press, 1999.

WADE, M.; HULLAND, J. Review: the resource-based view and information systems research: review, extension, and suggestions for future research. MIS Quarterly, v.28 n.1, p.107-142, Mar. 2004.

WAINER, J. 0 paradoxo da produtividade. In: RUBEN, G.; WAINER, J.; DWYER, T. (Org.). Informática, organizações e sociedade no Brasil. São Paulo: Cortez, 2003.

WERNERFELT, B. A resource-based view of the firm. Strategic Management Journal, v.5, n.2, 1984.

YIN R. Case study research: design and methods. 2nd ed. Thousand Oaks, CA: Sage Publications, 1994. 